\title{
Evaluation of Synergistic Interactions Between Cell-Free Supernatant of Lactobacillus Strains and Amikacin and Genetamicin Against Pseudomonas aeruginosa
}

\author{
Sargol Aminnezhad ${ }^{1}$; Rouha Kasra Kermanshahi ${ }^{2, *}$; Reza Ranjbar $^{3}$ \\ ${ }_{1}$ Young Researchers and Elites Club, Science and Research Branch, Islamic Azad University, Tehran, IR Iran \\ 2 Department of Biology, School of Science, Alzahra University, Tehran, IR Iran \\ ${ }^{3}$ Molecular Biology Research Center, Baqiyatallah University of Medical Sciences, Tehran, IR Iran \\ ${ }^{*}$ Corresponding author: Rouha Kasra Kermanshahi, Department of Biology, School of Science, Alzahra University, Tehran, IR Iran. Tel: +98-2188052709, Fax: +98-21880589, \\ E-mail: rkasra@yahoo.com
}

Received: December 4, 2013; Revised: March 16, 2014; Accepted: April 27, 2014

\begin{abstract}
Background: The indiscriminate use of antibiotics in the treatment of infectious diseases can increase the development of antibiotic resistance. Therefore, there is a big demand for new sources of antimicrobial agents and alternative treatments for reduction of antibiotic dosage required to decrease the associated side effects.

Objectives: In this study, the synergistic action of aminoglycoside antibiotics and cell-free supernatant (CFS) of probiotic (Lactobacillus rahmnosus and L. casei) against Pseudomonas aeruginosa PTCC 1430 was evaluated.

Materials and Methods: A growth medium for culturing of probiotic bacteria was separated by centrifugation. The antimicrobial effects of CFS of probiotic bacteria were evaluated using the agar well diffusion assay. The minimum inhibitory concentration(MIC) and minimum bactericidal concentration (MBC) were evaluated using the micro dilution method. Finally, an interaction between CFS and amikacin or gentamicin against $P$. aeruginosa PTCC 1430 was examined through the checkerboard method and fractional inhibitory concentration (FIC). Furthermore, CFSs from Lactobacillus strains were analyzed by reversed phase HPLC (RP-HPLC) for antimicrobial compounds. Results: The results showed a significant effect of CFS on the growth of P. aeruginosa. The MIC and MBC of CFS from L. casei were $62.5 \mu \mathrm{L} / \mathrm{mL}$ while the MIC and MBC of CFS from L. rhamnosus were $62.5 \mu \mathrm{L} / \mathrm{mL}$ and $125 \mu \mathrm{L} / \mathrm{mL}$, respectively. Using the FIC indices, synergistic interactions were observed in combination of CFS and antibiotics. Fractional Inhibitory Concentration indices of CFS from L. casei and aminoglycoside antibiotics were 0.124 and 0.312 while FIC indices of CFS from L. rhamnosus and aminoglycoside antibiotics were 0.124 and 0.56 , respectively showing a synergism effect. The results of RP-HPLC showed that CFS of Lactobacillus strains contained acetic acid, lactic acid and hydrogen peroxide $\left(\mathrm{H}_{2} \mathrm{O}_{2}\right)$.

Conclusions: Our findings indicate that probiotic bacterial strains of Lactobacillus have a significant inhibitory effect on the growth of $P$. aeruginosa PTCC 1430. The antimicrobial potency of this combination can be useful for designing and developing alternative therapeutic strategies against $P$. aeruginosa infections.
\end{abstract}

Keywords: Pseudomonas aeruginosa; Lactobacillus casei; Lactobacillus rhamnosus; Checkerboard Method

\section{Background}

Nowadays, much attention has been paid to infection and Pseudomonas aeruginosa is a top three opportunistic pathogen in hospitalized, immunocompromised, and cystic fibrosis patients (1). Infection caused by $P$. aerugino$s a$ is often life-threatening and difficult to treat because of its primary limited susceptibility to commonly used antimicrobial agents (2). It is necessary for the utilization of alternative antibacterial therapies against $P$. aeruginosa infections. Synergistic combinations of antibiotics and other antimicrobials may be effective against infections where the development of resistance and/or subsequent failure to monotherapy is prevalent associated with the prevention of the emergence of bacterial resistance $(3,4)$. Aminoglycosides are broad-spectrum antibiotics of high potency that have been traditionally used for the treatment of serious Gram-negative infections (5) and vital component of antipseudomonal chemotherapy implicated in the treatment of a variety of infections (6). These agents are bactericidal and exhibit synergy with other antimicrobial compounds.

One such preference is the possible therapeutic use of probiotics as an adjunct to chemotherapy (7). Probiotics are dietary supplements containing potentially useful yeasts or bacteria. According to the currently adopted description by food and agriculture organization of the united nations/world health organization (FAO/WHO) in 2001, probiotics are live microorganisms, which when administered in requisite amounts confer a health benefit on the host $(4,8)$. Supernatant of most Lactobacillus bacteria (LAB) such Lactobacillus casei and L. rahmnosus

Copyright (C) 2015, Ahvaz Jundishapur University of Medical Sciences. This is an open-access article distributed under the terms of the Creative Commons Attribution-NonCommercial 4.0 International License (http://creativecommons.org/licenses/by-nc/4.0/) which permits copy and redistribute the material just in noncommercial usages, provided the original work is properly cited. 
contains several antimicrobials including organic acids, hydrogen peroxide, aroma components, fatty acid and low-molecular-mass compounds which kill pathogens (9). Strains of Lactobacillus bacteria can produce organic acid through hetero fermentative pathways, and these compounds may interact with cell membranes, induce intracellular acidification and diffuse passively across the membrane and protein denaturation (10). Hydrogen peroxide $\left(\mathrm{H}_{2} \mathrm{O}_{2}\right)$ can act as a precursor to the production of bactericidal free radicals, such as superoxide $\left(\mathrm{O}_{2}{ }^{-}\right)$and hydroxyl $\left(\mathrm{OH}^{-}\right)$radicals, which can damage DNA as well as peroxidation of membrane lipids increases the permeability of the membrane (11).

The therapeutic role of probiotics in the P. aeruginosa (12-14), Staphylococcus aureus (15) and Salmonella $(7,8,16)$ infections have been reported. Treatments with combination of probiotics and antibiotic have been reported to be successful in the management of Helicobacter pylori infection (17). A combination therapy by probiotic and antibiotic may provide higher antimicrobial activity and decrease the dose of antibiotic required in addition to replenish the intestinal flora thereby providing benefit to the host and also decrease other antibiotic side effects (18). In the present study, the possible synergistic interactions between the cell-free Lactobacillus supernatant (CFS) and amikacin or gentamicin on their antibacterial potencies against $P$. aeruginosa were evaluated.

\section{Objectives}

This study aimed to investigate the antimicrobial effect of CFS from Lactobacillus strains on the growth of P. aeruginosa and evaluate synergistic interactions between CFS and amikacin or gentamicin against $P$. aeruginosa and also to identify some of the antimicrobial compounds that Lactobacillus strains produce.

\section{Materials and Methods}

\subsection{Bacterial Strains and Growth Conditions}

Pseudomonas aeruginosa PTCC 1430, Lactobacillus casei PTCC 1608 and Lactobacillus rahmnosus PTCC 1637 were procured from Iranian Type Culture Collection (PTCC). $P$. aeruginosa subcultured in nutrient broth (NB) (Merck, Germany) for 24 hours at $37^{\circ} \mathrm{C}$. L. casei and L. rahmnosus were grown in De Mann Rogosa Sharpe (MRS) broth (Mer$\mathrm{ck}$, Germany) for 48 hours at $37^{\circ} \mathrm{C}$ under anaerobic conditions in a Coy Laboratory anaerobic chamber (19).

\subsection{Antibiotic Susceptibility Testing}

Qualitative antibacterial susceptibility of the microorganisms was determined according to the standard disk diffusion (Kirby-Bauer) method (20). using the paper disk including ( $\mu \mathrm{g} / \mathrm{disc})$ : azithromycin (15); ceftriaxone (21); imipenem (10); amikacin (21); chloramphenicol (21); ceftazidim (21); tobramycin (10); gentamycin (10) andcip- rofloxacin (5) purchased from Mast Co (Liverpool, UK). Microbial suspensions with 106 colony forming units $(\mathrm{CFU} / \mathrm{mL})$ of each Lactobacillus strain in NB were prepared on a De Mann Rogosa Sharpe agar plate. The plates were incubated at $37^{\circ} \mathrm{C}$ for 48 hours in anaerobic condition and examined for the inhibition zone diameter appearing around each antibiotic disc. A test was carried out thrice for each antibiotic agent . Inhibitory zone diameters were compared with the standards provided by the National Committee for Clinical Laboratory Standards (NCCLS) (19). Antibiotic sensitivity of $P$. aeruginosa was also determined by the same method using the Muller Hilton agar.

\subsection{In Vitro Inhibitory Effect of Cell-Free Superna- tants and Antibiotics}

\subsubsection{Preparation of Cell-Free Supernatant From Lacto- bacilli Strains}

Cell-free supernatant was prepared according to the method Ogunbanwo (22). Lactobacillus was grown in MRS broth ( $\mathrm{pH}$ 5.7) for 48 hours at $37^{\circ} \mathrm{C}$ in anaerobic condition. Cell-free supernatant was obtained by centrifuging the culture at $15000 \mathrm{rpm}$ for 15 minutes at $4^{\circ} \mathrm{C}$ and then filtered through $0.45 \mu \mathrm{m}$ filters (Millipore, Bedford, MA).

\subsubsection{Agar Well Diffusion Assay}

Antimicrobial activities of CFS were determined by the agar well diffusion assay. In this method, bacterial inoculum colonies from overnight nutrient agar were used to make suspension of the test organisms to be equivalent to the $0.5 \mathrm{McF}$ arland standards. Wells with a $6-\mathrm{mm}$ diameter were punched in the agar plates and were filled with $100 \mu \mathrm{L}$ of different concentrations of CFS $(10 \mu \mathrm{L} / \mathrm{mL}$, $50 \mu \mathrm{L} / \mathrm{mL}$ and $100 \mu \mathrm{L} / \mathrm{mL}$ ). The plates were then incubated at $37^{\circ} \mathrm{C}$ for 24 hours and the diameter zones of inhibition were assessed (23). The experiments were repeated three times and the mean values of the diameter of inhibition zone with \pm standard deviation were calculated.

\subsubsection{Determination of Minimum Inhibitory Concentra- tions}

The minimum inhibitory concentrations (MICs) were determined by micro dilution assay according to the procedures recommended by the Clinical and Laboratory Standards Institute (formerly the National Committee for Clinical Laboratory Standards 2006). Dilutions of the antibiotics (amikacin or gentamicin), ranging from 0.125 - $256 \mu \mathrm{g} / \mathrm{mL}$ in Muller Hinton Broth (MHB) were prepared by incorporating the antibiotic stock solution into the Muller Hinton Broth. Dilutions of the CFS in the range of $0.12-250 \mu \mathrm{L} / \mathrm{mL}$ were also prepared by incorporation of the CFS into Muller Hinton Broth. Each plate includes positive and negative controls (19). Briefly, a bacterial in- 
Aminnezhad S et al.

oculum $(100 \mu \mathrm{L})$, corresponding to $5 \times 10^{5} \mathrm{CFU} / \mathrm{mL}$, was added to $100 \mu \mathrm{L}$ of serial two-fold dilutions of the antibiotics in the wells of microtiter plates. For negative controls, $100 \mu \mathrm{L}$ of $256 \mu \mathrm{g} / \mathrm{mL}$ concentration of the antibiotics was added to100 $\mu \mathrm{L}$ MHB in the wells of micro titer plates. Furthermore, for positive controls $100 \mu \mathrm{L}$ bacterial inoculum was added to $100 \mu \mathrm{L}$ MHB in the wells of microtiter plates.

The final volume of each well was $200 \mu \mathrm{L}$. The plates were incubated at $37^{\circ} \mathrm{C}$ for 24 hours. The MIC was defined as "the lowest concentration of antibiotic which can inhibit visible growth of microorganism". Afterwards, 100 $\mu \mathrm{L}$ of liquid from each well without visible growth on to Mueller-Hinton agar (MHA) for determination of MBC was used and incubated at $37^{\circ} \mathrm{C}$ for $48-72$ hours. Finally, the lowest concentration of antimicrobial agent being able to reduced $99.9 \%$ of the bacteria was assessed as MBC. Experiments were done in triplicate.

\subsubsection{Fractional Inhibitory Concentration Determina-} tion and the Interaction Effect of Two Antimicrobial Agents (Antibiotics + Cell Free Supernatant) on Test Bacteria

Drug interactions were assessed using a checkerboard microdilution method. The concentrations of antimicrobial agent were typically ranged from four or five below the expected MIC to twice the anticipated MIC as the 45 degree line in Figure 1 (each square represents one plate). The interactions were assessed using two-fold dilutions of each antimicrobial agent, concentration of MIC point and dilution lower than it for each antimicrobial agent alone. Inocula were prepared spectrophotometrically and further diluted to obtain final concentrations $0.5 \times$ $10^{6} \mathrm{CFU} / \mathrm{mL}$. Each microdilution well included $100 \mu \mathrm{L}$ of the diluted (two times) drug concentrations of both antimicrobials (antibiotics and CFS) was inoculated with 100 $\mu \mathrm{L}$ of the diluted (two times) inoculum suspension (final volume of each well, $200 \mu \mathrm{L}$ ). The trays were incubated at $37^{\circ} \mathrm{C}$, and the results were read at 24 hours visually using an ELISA reader system (statfax-2100, Awareness Technology Inc., USA).

The FIC index was then calculated using the observing equation with summing the separate FICs for each drug present in that well:

$\mathrm{FIC}_{\text {index }}=\mathrm{FIC}_{\mathrm{A}}+\mathrm{FIC}_{\mathrm{B}}=$ MIC $(\mathrm{A}$ in presence of $\mathrm{B}) / \mathrm{MIC}(\mathrm{A}$ alone) + MIC (B in presence of A) / MIC (B alone)

Where $A$ is the concentration of $\operatorname{drug} A$ in well that is the lowest inhibitory concentration in its row, MIC ${ }_{A}$ is the MIC of the organism to drug A alone, and FIC ${ }_{A}$ is the FIC of drug A. Also, B is the concentration of drug B in a well that is the lowest inhibitory concentration in its column; $\mathrm{MIC}_{\mathrm{B}}$ and ${ }_{\text {FIC }}$ are defined in the same fashion for drug A. According to this method, synergism has traditionally been defined as an FIC index of 0.5 or less and additively as a FIC index of 1.0; antagonism has been defined as a FIC index of 2.0. Synergy was further subclassified as marked (FIC $\leq 0.50$ ) and weak (FIC index, between 0.50 and 1.0)(24).

Figure 1. Simplified Checker-Board Method

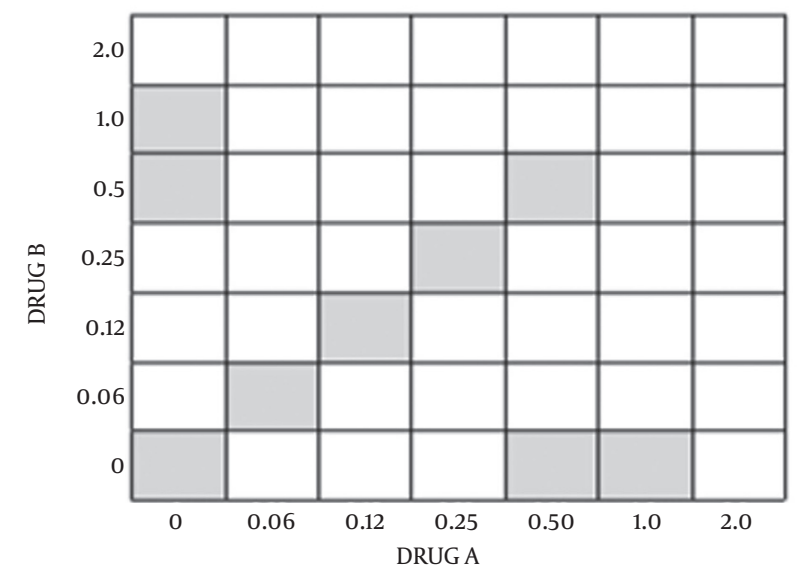

Minimum inhibitory concentration (MIC) of drugs A and B are considered as $1 \mu \mathrm{g} / \mathrm{mL}$.

\subsection{Analysis of Cell-Free Supernatant From Lacto- bacillus Strains for Antimicrobial Compounds}

Cell-free supernatants of each strain of L. Casei, and L. rhamnosus were prepared according to the method of Ogunbanwo (22). The supernatant was filtered using $0.45 \mu \mathrm{m}$ Millipore filters and 2 aliquots were stored at $20^{\circ} \mathrm{C}$ until analyzed for antimicrobial compounds, including lactic acid, acetic acids and hydrogen peroxide $\left(\mathrm{H}_{2} \mathrm{O}_{2}\right)$ (Sigma) using Reversed-Phase high-Performance Liquid Chromatography (RP-HPLC) (25). Standard stock solutions of lactic acid pKa $=3.086(5.2 \mathrm{mg} / \mathrm{mL})$, acetic acid $\left(5.4 \mathrm{mg} / \mathrm{mL}\right.$ ) and $\mathrm{H}_{2} \mathrm{O}_{2}(35 \%)$ were prepared in ultrapure water and stored at $4^{\circ} \mathrm{C}(26)$. Standard solutions of organic acids and $\mathrm{H}_{2} \mathrm{O}_{2}$ were determined by RP-FPLC, using an AKTA purifier system (GE Healthcare) equipped with YMC-Triart C18 $(250 \times 4.6 \mathrm{mmI} . \mathrm{D}, \mathrm{S}-5 \mathrm{um}, 12 \mathrm{~nm})$. The degassed mobile phase of $0.009 \mathrm{M} \mathrm{KH}_{2} \mathrm{PO}_{4}$ adjusted by phosphoric acid to $\mathrm{pH} 2.06$.filtered through a $0.45 \mu \mathrm{m}$ membrane filter was used at a flow rate of $1 \mathrm{~mL} /$ minutes. The wavelength of detection was optimized at $210 \mathrm{~nm}$ and the sample injection was $50 \mu \mathrm{L} .(25,27)$. Moreover, the CFSs from Lactobacillus strains were analyzed by RP-HPLC under the same conditions $(25,28)$.

\subsection{Statistical Analysis}

Data were analyzed using Graph Pad Prism version 5 (Graphpad Software In, San Deigo, USA). All data were expressed as Mean \pm S.D. Statistical analyses were evaluated by one-way analysis of variance (ANOVA). Significance level for all tests was considered $(\mathrm{P}<0.05)$.

\section{Results}

Antibiotic susceptibility pattern of the tested microor- 
ganisms was shown that $P$. aeruginosa was sensitive to amikacin and gentamicin, while L. casei and L. rhamnosus were resistance to the amikacin and gentamicin (Table 1). The antimicrobial activities of CFS from Lactobacillus strains in different concentration were determined using the agar well diffusion assay summarized in Table 2 Figure 2 .

Table 1. Antibiotic Susceptibility Pattern of Test Lactobacillus Strains Including Lactobacillus rahmnosus, and Lactobacillus casei, and Standard Strain of Pseudomonas aeruginosa as Determined by the Disc-Diffusion Technique a

\begin{tabular}{|c|c|c|c|c|}
\hline \multirow[t]{2}{*}{ Antibiotics } & \multirow[t]{2}{*}{ Concentration, ug/disc } & \multicolumn{2}{|c|}{ Test Lactobacillus Strains } & \multirow[t]{2}{*}{ P. aeruginosa PTCC 1430} \\
\hline & & L. casei PTCC 1608 & L. rahmnosus PTCC 1637 & \\
\hline Azithromycin & 15 & $S$ & $S$ & $\mathrm{R}$ \\
\hline Ciprofloxacin & 5 & S & $S$ & S \\
\hline Gentamicin & 10 & $\mathrm{R}$ & $\mathrm{R}$ & S \\
\hline Ceftazidim & 30 & S & $\mathrm{R}$ & S \\
\hline Ceftriaxone & 30 & $S$ & $S$ & S \\
\hline Amikacin & 30 & $\mathrm{R}$ & $\mathrm{R}$ & $S$ \\
\hline Tobramycin & 10 & $\mathrm{R}$ & $S$ & S \\
\hline Chloramphenicol & 30 & $S$ & $S$ & $\mathrm{R}$ \\
\hline Imipenem & 10 & $\mathrm{R}$ & $\mathrm{R}$ & $S$ \\
\hline
\end{tabular}

a Abbreviations: R, resistant;S, sensitive.

Table 2. Inhibition Zone Diameters of CFS From Lactobacillus Strains Against Pseudomonas aeruginosa PTCC 1430 a,b

\begin{tabular}{lcccc}
\hline Concentrations of CFS, $\boldsymbol{\mu L} / \mathbf{m L}$ & $\mathbf{1 0}$ & $\mathbf{5 0}$ & $\mathbf{1 0 0}$ & PValue \\
\hline L. casei PTCC $\mathbf{1 6 0 8}$ & $6^{\mathrm{C}}$ & $14 \pm 0.70$ & $20.33 \pm 0.57$ & 0.0003 \\
L. rahmnosus PTCC 1637 & 6 & $12.33 \pm 0.57$ & $17.33 \pm 0.57$ & 0.0003 \\
Blank (MRS medium) & 6 & 6 & 6 & - \\
\hline
\end{tabular}

a Abbreviations: CFS, Cell-Free Supernatant; MRS, De Mann Rogosa Sharpe.

b Data are presented as No. (\%).

${ }^{\mathrm{C}}$ Zone of inhibition, including the diameter of the well $(6 \mathrm{~mm})$; mean value of three independent experiments.

Figure 2. Zone of Inhibition of Growth of Pseudomonas aeruginosa Produced by Different Concentrations of CFS From L. casei (A) and L. rahmnosus (B) by Agar Well Diffusion Method
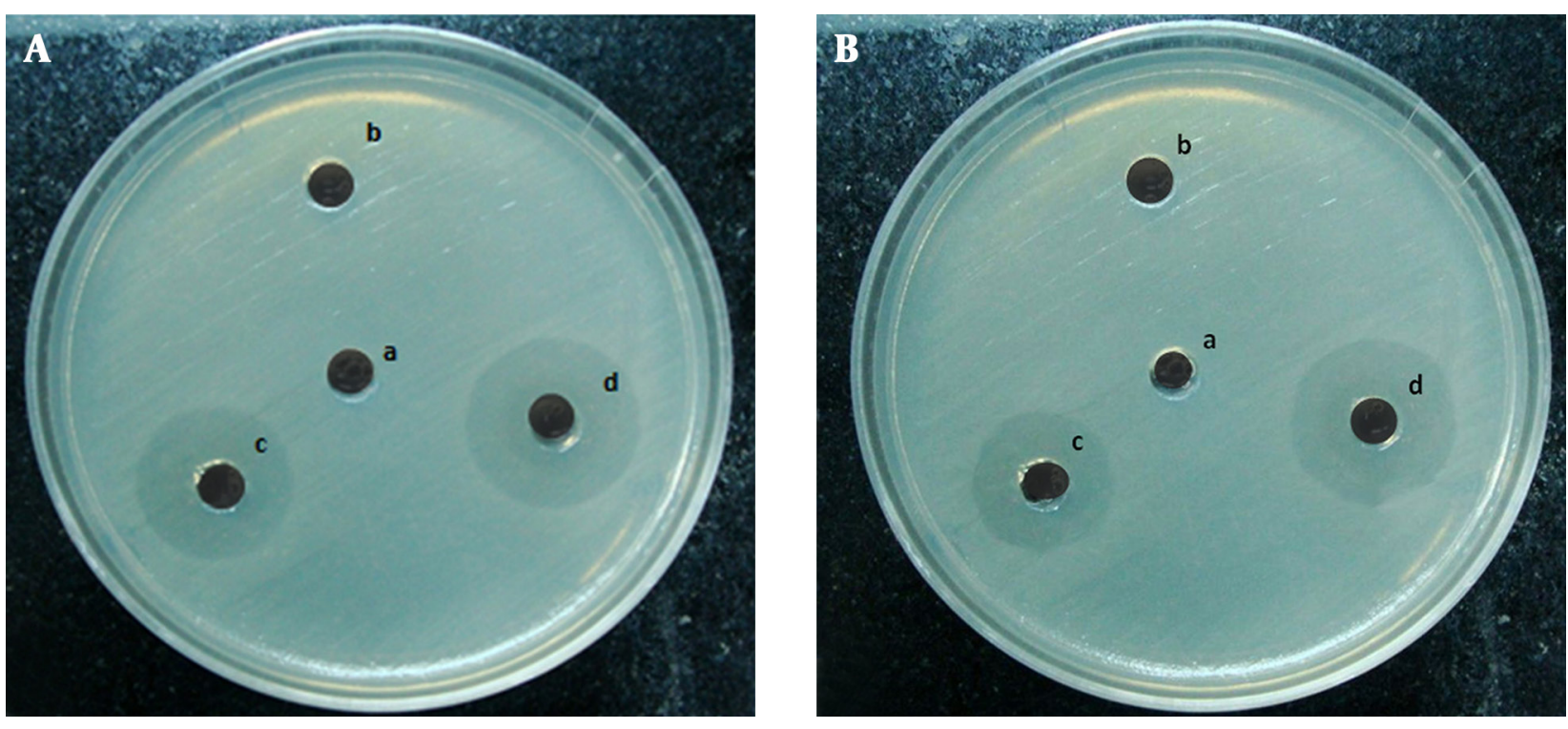
The activity quantitatively assessed on the basis of the inhibition zone, and their activity index was also calculated along with the minimum inhibitory concentration (MIC). The results of the MIC and minimum bactericidal concentration (MBC) of the CFS and antibiotics were determined by the microdilution method and are shown in Table 3. Also, the FIC value for CFS and antibiotics were shown in Table 4. All antimicrobial combinations demonstrated synergistic actions against $P$. aeruginosa. Only the combination of CFS from $L$. casei and gentamicin demonstrated indifference action.

An antimicrobial compound in the CFS of Lactobacillus was identified by comparison of retention times and the UV absorption spectra with those obtained from the cor- responding standards. Peaks of standard solution were observed at (6.00 \pm 0.13$)$ minutes for lactic acid, (6.02 \pm $0.06)$ minutes for acetic acid, and (3.06 $\pm 0.0 .6)$ minutes for $\mathrm{H}_{2} \mathrm{O}_{2}$, for an average of 5 injections (Table 5). As a control, the antimicrobial compound profile of the sterile MRS medium was analyzed (Figure 3A). Compared with this control chromatogram, the CFS of L. casei and L. rhamnosus (Figure $3 \mathrm{~B}$ and $3 \mathrm{C}$ ) contained the same peaks that corresponding to acetic acid (AA) (6.23 minutes), lactic acid (LA) (5.73) and $\mathrm{H}_{2} \mathrm{O}_{2}$ (3.02 minutes). This study showed that antimicrobial compound is already present in the sterile MRS medium; however, significant changes were observed in the amount of the compound during growth of Lactobacillus strains ( $\mathrm{P}<0.05$ ) (Figures 3A, 3B and 3C).

Table 3. The Minimum Inhibitory Concentration and Minimum Bactericidal Concentration of Antimicrobial Agents on the Pseudomonas aeruginosa PTCC1430 a,b

\begin{tabular}{lcccc}
\hline MIC and MBC & \multicolumn{2}{c}{ CFS, $\mu \mathrm{L} / \mathbf{m L}^{\mathrm{C}}$} & \multicolumn{2}{c}{ Antibiotics $(\mu \mathrm{g} / \mathrm{mL})$} \\
\cline { 2 - 6 } & L.casei PTCC 1608 & L.rahmnosus PTCC 1637 & Amikacin & Gentamicin \\
\hline MIC & 62.5 & 62.5 & 1 & 8 \\
MBC & 62.5 & 125 & 16 & 4 \\
\hline
\end{tabular}

a All determinations were done in triplicate.

b Abbreviations: CFS, Cell-Free Supernatant; MBC, minimum bactericidal concentration; and MIC, Minimum Inhibitory Concentrations.

c CFS dissolved in Cation Adjusted Muller Hinton Broth.

Table 4. Fractional Inhibitory Concentration Determination and Interaction Effect of Two Antimicrobial Agents (Antibiotics + Cel Free Supernatant) on the Pseudomonas aeruginosa PTCC $1430^{\text {a }}$

\begin{tabular}{lcccccc}
\hline $\begin{array}{l}\text { Combination of } \\
\text { Two Compounds }\end{array}$ & $\begin{array}{c}\text { MIC A (Alone) } \\
(\mu \mathrm{L} / \mathbf{m L})\end{array}$ & $\begin{array}{c}\text { MIC B (Alone) } \\
(\mu \mathrm{L} / \mathbf{m L})\end{array}$ & $\begin{array}{c}\text { MIC A (in the Pres- } \\
\text { ence of } \mathbf{B})(\mu \mathrm{L} / \mathbf{m L})\end{array}$ & $\begin{array}{c}\text { MIC B (in the Pres- } \\
\text { ence of } \mathbf{A})(\boldsymbol{\mu} \mathbf{L} / \mathbf{m L})\end{array}$ & $\begin{array}{c}\text { Checkerboard } \\
\text { FIC Index }\end{array}$ & $\begin{array}{c}\text { Checkerboard } \\
\text { Effect }\end{array}$ \\
\hline $\begin{array}{l}\text { L.Casei and Genta- } \\
\text { micin }\end{array}$ & 62.5 & 1 & 0.39 & 0.25 & 0.312 & marked synergy \\
$\begin{array}{l}\text { L. rhamnosus and } \\
\text { Gentamicin }\end{array}$ & 62.5 & 1 & 0.39 & 0.0625 & 0.124 & marked synergy \\
$\begin{array}{l}\text { L. casei and Ami- } \\
\text { kacin }\end{array}$ & 62.5 & 8 & 0.39 & 0.5 & 0.124 & marked synergy \\
$\begin{array}{l}\text { L. rhamnosus and } \\
\text { Amikacin }\end{array}$ & 62.5 & 8 & 0.39 & 4 & 0.56 & weak synergy \\
\hline
\end{tabular}

a Abbreviations: FIC, Fractional Inhibitory Concentration; and MIC, Minimum Inhibitory Concentrations.

Table 5. Determination of Antimicrobial Compounds in Cell-Free Supernatant From Lactobacillus Strains Using Reversed phase HPLC Method

\begin{tabular}{|c|c|c|c|c|}
\hline $\begin{array}{l}\text { CFS From Lactobacillus, Antimicrobial } \\
\text { Compound }\end{array}$ & Retention Time, mL & Peak Start, mL & Peak End, mL & $\begin{array}{c}\text { Area/Total Area } \\
\text { (Volume (\%)) }\end{array}$ \\
\hline \multicolumn{5}{|l|}{ Blank(MRS Medium) } \\
\hline $\mathrm{H}_{2} \mathrm{O}_{2}$ & 3.02 & 2.65 & 3.19 & 13.09 \\
\hline Lactic acid pKa = 3.086 & 5.79 & 5.57 & 6.06 & 3.68 \\
\hline Acetic acidpKa $=4.76$ & 6.24 & 6.06 & 6.66 & 3.80 \\
\hline \multicolumn{5}{|l|}{ L. casei PTCC 1608} \\
\hline $\mathrm{H}_{2} \mathrm{O}_{2}$ & 3.02 & 2.63 & 3.35 & 16.56 \\
\hline Lactic acid pKa = 3.086 & 5.73 & 5.53 & 6.08 & 12.06 \\
\hline Acetic acidpKa = 4.76 & 6.23 & 6.08 & 6.69 & 3.6 \\
\hline \multicolumn{5}{|l|}{ L. rahmnosus PTCC 1637} \\
\hline $\mathrm{H}_{2} \mathrm{O}_{2}$ & 3.01 & 2.65 & 3.30 & 20.64 \\
\hline Lactic acid & 5.60 & 5.23 & 5.92 & 12.193 \\
\hline Acetic acid & 6.07 & 5.92 & 6.50 & 3.22 \\
\hline
\end{tabular}


Figure 3. Reversed Phase HPLC Profiles

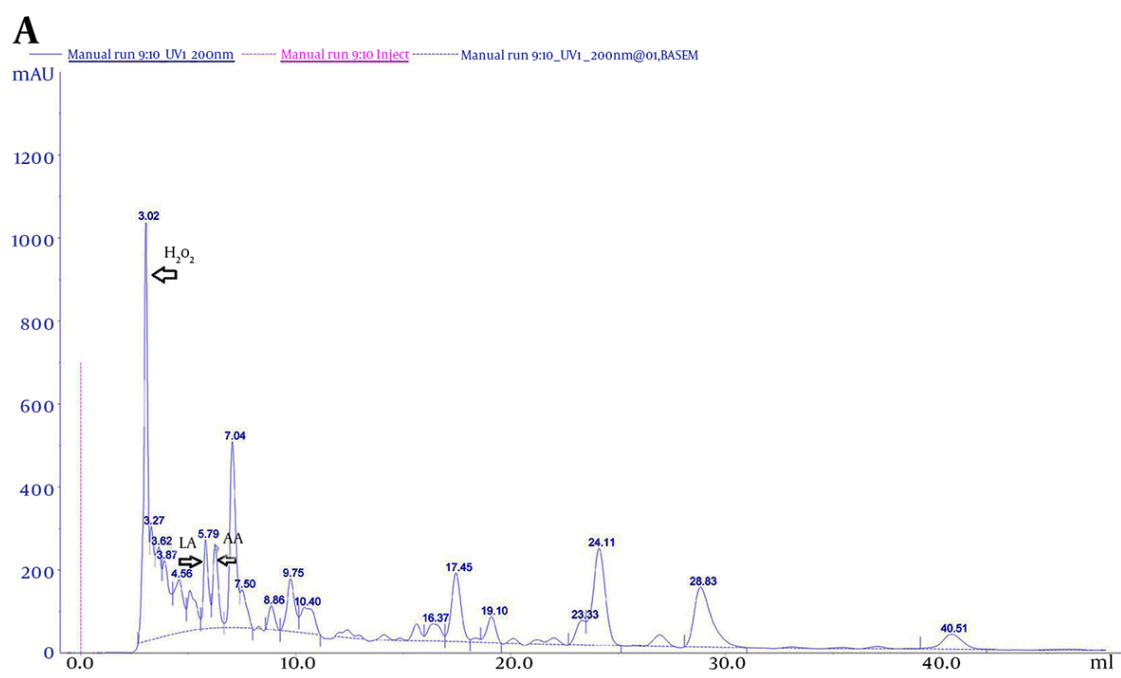

B

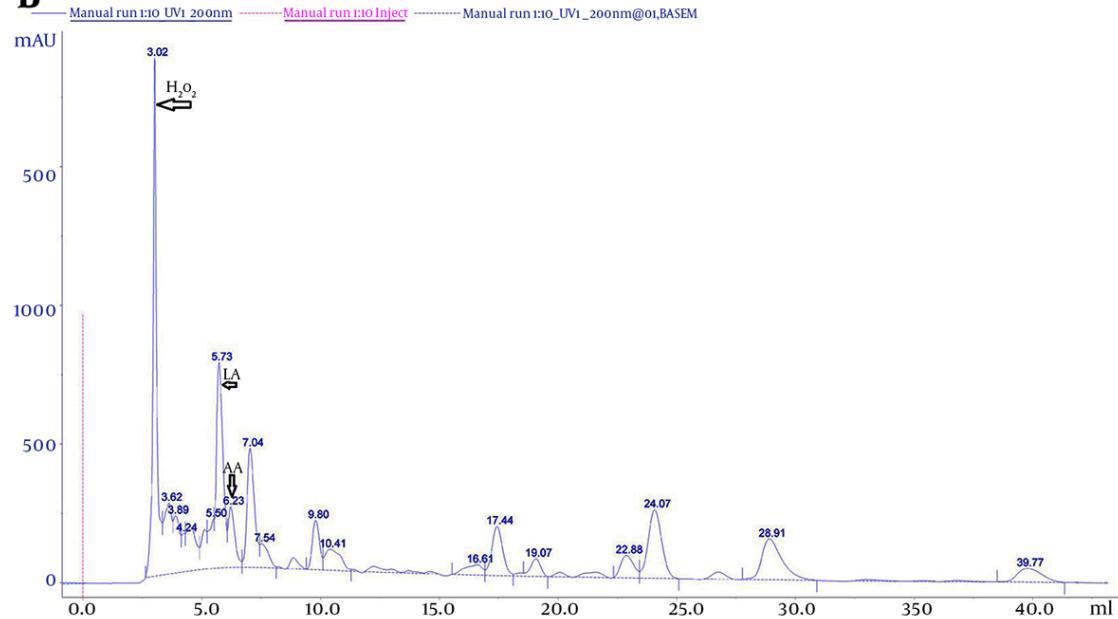

C

C Manual run 4:10 UV1 200nm - Manual run 4:10 Inject - …...Manual run 4:10_UV1_200nm@01,BASEM

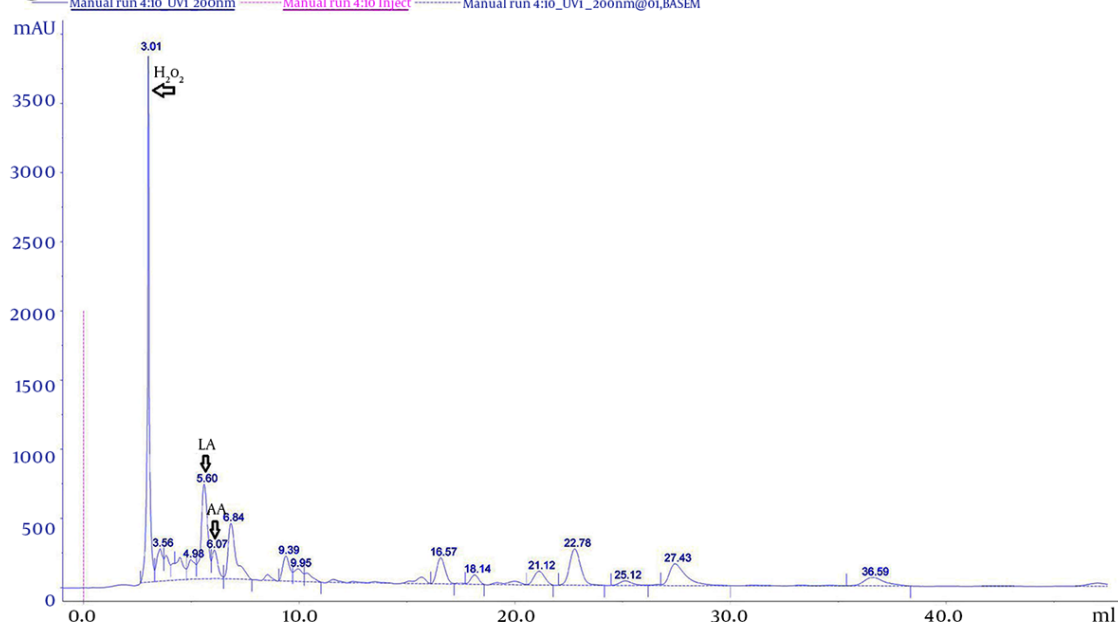

A, Cell-free supernatant of sterile De Man-Rogosa Sharpe medium; B, Lactobacillus casei PTCC 1608; C, Lactobacillus rahmnosus PTCC 1637. The x-axis refers to the retention time of the antimicrobial compound (in minutes): lactic acid (LA), acetic acid (AA) and hydrogen peroxide ( $\mathrm{H}_{2} \mathrm{O}_{2}$ ). Column: ymc-triart C18 ( 250 x $4.6 \mathrm{~mm}$, HP, particle size $5 \mu \mathrm{m}$, flow rate $1 \mathrm{~mL} /$ minute) Detection: diode array detector set at $210 \mathrm{~nm}$. 


\section{Discussion}

Pseudomonas aeruginosa infection is one of the most difficult or impossible to eradicate infections and therefore this bacterial infection needs new therapeutic protocol and strategy $(12,29)$. An antimicrobial combination has been utilized as an effective therapeutic strategy by using of various mechanisms of action (18). Aminoglycosides are known Frontline antibiotics in the treatment of Gram-negative bacterial infections there are potent antibiotics that inhibit protein synthesis by binding to the bacterial $30 \mathrm{~S}$ ribosomal subunit (30). Since emerging reports showed increased prevalence of resistance against these drugs as observed, it seems necessary to use combinations of aminoglycosides with other antimicrobial agents against $P$. aeruginosa. A synergistic combination of aminoglycosides (gentamicin, tobramycin and amikacin), fluoroquinolone (ciprofloxacin) and penicillins (carbenicillin) has been used to treat $P$. aeruginosa infections (30). Moreover, some P. aeruginosa strains have been reported to have resistance to aminoglycoside antibiotics $(31,32)$.

In the present study, the possible effects of CFS on the bactericidal activities of two antibiotics from aminoglycosides were evaluated. The study of aminoglycoside antibiotics in combination with probiotics might prove the benefit of using a combination with the lower dose of antibiotic alone.

In the present study, we put forward the hypothesis that whether treatment with combination of cell-free supernatant from L. casei and L rahmnosus with aminoglycoside antibiotics have higher antimicrobial activity against $P$. aeruginosa or not. Keeping in view the application of probiotics to be used in conjunction with an antibiotic, the first criteria which a Lactobacillus strains needs to fulfill is that it should be resistant to that particular antibiotic to avoid the direct killing of the probiotic strain. After determination of resistance and sensitivity of L. casei and L. rahmnosus and P. aeruginosa to aminoglycosides, the combination of cell-free supernatant from $L$. casei and L. rahmnosus and aminoglycosides was further tested to evaluate the possible synergistic effect against P. aeruginosa.

Aminoglycosides interfere and affect the bacterial protein synthesis through binding to the ribosomal subunits of the bacterial cell, in addition, an increase of reactive oxygen species in the bacterial cells in response to ciprofloxacin has been shown (33). In previous studies, separation, purification and identification of antimicrobial agents produced by LAB, were conducted by several techniques (17, 34-36) and in this study, the presence of lactic acid, acetic acid and $\mathrm{H}_{2} \mathrm{O}_{2}$ in CFS of $L$. casei and $L$. rahmnosus was confirmed by RP-HPLC analysis. The organic acid acts by collapsing the electrochemical proton gradient, and $\mathrm{H}_{2} \mathrm{O}_{2}$ by peroxidation of membrane lipids thus altering the cell membrane permeability which results in disruption of substrate transport systems (37-39).
Alakomi et al. (40) also found that lactic acid, in addition to its antimicrobial property due to the lowering of the $\mathrm{pH}$, also functions as a membrane-permeabilizing of the Gram-negative bacterial outer membrane and may act as a potentiator of the effects of other antimicrobial substances. In the present study, Synergistic interactions were observed between CFS of L. casei and L. rahmnosus with aminoglycoside antibiotics. These antibacterial mechanisms of $\mathrm{H}_{2} \mathrm{O}_{2}$ and aminoglycoside antibiotics to produce reactive oxygen species (ROS) might have acted cooperatively with each other, leads to a higher bactericidal effect of the combination in support of our findings. Goswami et al. (41) have also reported that the involvement of superoxide anion $\left(\mathrm{O}_{2}^{-}\right)$and hydrogen peroxide $\left(\mathrm{H}_{2} \mathrm{O}_{2}\right)$ in the antibacterial action of ciprofloxacin was analyzed using superoxide dismutase, catalase, and alkyl hydro peroxide reductase knockout strains of $E$. coli.

Fractional inhibitory concentration (FIC) index also further substantiated the synergistic effect between the two compounds. We have previously demonstrated that CFS also reduced the MICs of gentamicin and amikacin. This synergistic effect was also confirmed by checkerboard testing (Figure 3). All two aminoglycoside antibiotics had FIC indices less than 0.5 , indicating synergetic interaction between CFS and the antibiotic. Probiotics for the prevention and treatment of a wide variety of diseases is supported. Given the strong evidence that the clinical efficacy of probiotics and their increasing use in the treatment of diseases, a thorough understanding of their risks and benefits is imperative $(42,43)$. There are some theoretical adverse risks that are discussed with respect to the use of probiotics in humans $(42,43)$. These theoretical risks include the potential for transmigration and the fact that colonization with probiotics may have a negative impact on gastrointestinal physiology and function, including metabolic and physiologic effects $(44,45)$. Some of studies have shown that a number of probiotics that have been identified as the cause bacteremia or endocarditis include: L. plantarum, L. rahmnosus, L. casei, $L$. salivarius, L. paracasei, and L. acidophilus $(46,47)$.

The most common side effects of Lactobacillus are found in patients with "short bowel syndrome" (or, sometimes, short gut syndrome) $(47,48)$. These side effects have been seen in a patient who had HIV infection and Hodgkin disease (49) and infection after a bone-marrow transplant (50). The presence of transferable antibiotic resistance genes in probiotics and transfer these genes via horizontal gene transfer as a major area of concern has been the potential for antibiotic-resistance transfer in the gastrointestinal tract that might take place between probiotics and a less innocuous member of the gut microbial community $(51,52)$.

\section{Acknowledgements}

The authors would like to express their appreciations to Ms. O. Bagheri and they also would like to thank Mr. J. 
Rashidian and Mr. M. Mirzai for their technical support.

\section{Authors' Contributions}

Sargol Aminnezhad: designed and coordinated the study, participated in most of the experiments and prepared the manuscript. Sargol Aminnezhad, Rouha Kasra Kermanshahi, Reza Ranjbar: provided assistance for the design of the study, coordinated and carried out all the experiments and participated in the manuscript preparation. All authors have read and approved the content of the manuscript.

\section{References}

1. Davis PB, Drumm M, Konstan MW. Cystic fibrosis. Am J Respir Crit Care Med.1996;154(5):1229-56.

2. Vojtova V, Kolar M, Hricova K, Uvizl R, Neiser J, Blahut L, et al. Antibiotic utilization and Pseudomonas aeruginosa resistance in intensive care units. New Microbiol. 2011;34(3):291-8.

3. Khalil H, Chen T, Riffon R, Wang R, Wang Z. Synergy between polyethylenimine and different families of antibiotics against a resistant clinical isolate of Pseudomonas aeruginosa. Antimicrob Agents Chemother. 2008;52(5):1635-41.

4. Ibezim EC, Esimone CO, Okorie O, Onyishi IV, Nnamani PO, Brown $\mathrm{SA}$, et al. A study of the in-vitro interaction of co-trimoxazole and ampicillin using the checke board method. Afr J Biotechnol. 2006;5:1284-8.

5. Hermann T. Aminoglycoside antibiotics: old drugs and new therapeutic approaches. Cell Mol Life Sci. 2007;64(14):1841-52.

6. Murray PR, Rosenthal KS, Kobayashi GS, Pfaller MA. Medical microbiology. 4th edSt. Louis: Mosby; 2002.

7. Rishi P, Preet S, Kaur P. Effect of L. plantarum cell-free extract and co-trimoxazole against Salmonella Typhimurium: a possible adjunct therapy. Ann Clin Microbiol Antimicrob. 2011;10:9.

8. Bergonzelli GE, Blum S, Brussow H, Corthesy-Theulaz I. Probiotics as a treatment strategy for gastrointestinal diseases? Digestion. 2005;72(1):57-68.

9. Gibbs PA. Novel uses for lactic acid fermentation in food preservation. Appl Bacteriol .1987;63:51-8.

10. Huang L, Forsberg CW, Gibbins LN. Influence of External pH and Fermentation Products on Clostridium acetobutylicum Intracellular pH and Cellular Distribution of Fermentation Products. Appl Environ Microbiol.1986;51(6):1230-4.

11. Byczkowski JZ, Gessner T. Biological role of superoxide ion-radical. Int J Biochem. 1988;20(6):569-80.

12. Jamalifar H, Rahimi H, Samadi N, Shahverdi A, Sharifian Z, Hos seini F, et al. Antimicrobial activity of different Lactobacillus species against multi- drug resistant clinical isolates of Pseudomonas aeruginosa. Iran J Microbiol. 2011;3(1):21-5.

13. Percival M. Choosing a probiotic supplement. Clin Nutr Insights 1997;6:1-4

14. Valdez JC, Peral MC, Rachid M, Santana M, Perdigon G. Interference of Lactobacillus plantarum with Pseudomonas aeruginosa in vitro and in infected burns: the potential use of probiotics in wound treatment. Clin Microbiol Infect. 2005;11(6):472-9.

15. Gan BS, Kim J, Reid G, Cadieux P, Howard JC. Lactobacillus fermentum RC-14 inhibits Staphylococcus aureus infection of surgical implants in rats. J Infect Dis. 2002;185(9):1369-72.

16. Rishi P, Kaur S, Bhalla MPS, Preet S, Tiwari RP. Selection of probiotic Lactobacillus acidophilus and its prophylactic activity against murine Salmonellosis. Int J Pro Pre. 2008;3(2):89-98.

17. Sgouras D, Maragkoudakis P, Petraki K, Martinez-Gonzalez B, Eriotou E, Michopoulos S, et al. In vitro and in vivo inhibition of Helicobacter pylori by Lactobacillus casei strain Shirota. Appl En viron Microbiol. 2004;70(1):518-26.

18. Rybak MJ, McGrath BJ. Combination antimicrobial therapy for bacterial infections. Guidelines for the clinician. Drugs. 1996;52(3):390-405.

19. Clinical and Laboratory Standards Institute.. Methods for dilution antimicrobial susceptibility tests for bacteria that grow aerobically. 6 th ed. approved standard editor. Wayne: CLSI; 2003.

20. Bauer AW, Kirby WM, Sherris JC, Turck M. Antibiotic susceptibility testing by a standardized single disk method. Am J Clin Pathol. 1966;45(4):493-6.

21. Anderson EL, Gramling PK, Vestal PR, Farrar WJ. Susceptibility of Pseudomonas aeruginosa to tobramycin or gentamicin alone and combined with carbenicillin. Antimicrob Agents Chemother 1975;8(3):300-4.

22. Ogunbanwo ST, Sanni AI, Onilude AA. Characterization of bacteriocin produced by Lactobacillus plantarum $\mathrm{F} 1$ and Lactobacillus brevis OG1. Afr J Biotechnol . 2003;2(8):219-27.

23. Nitisinprasert S, Nilphai V, Bunyun P, Sukyai P, Doi K, Sonomoto $\mathrm{K}$. Screening and identification of effective thermotolerant lactic acid bacteria producing antimicrobial activity against Escherichia coli and Salmonella sp.resistant to antibiotics. Kasetsart J. 2000;34(3):387-400.

24. European committee for antimicrobial susceptibility testing. Terminology relating to methods for the determination of susceptibility of bacteria to antimicrobial agents.: Eucast; 2000

25. Coda R, Cassone A, Rizzello CG, Nionelli L, Cardinali G, Gobbetti M. Antifungal activity of Wickerhamomyces anomalus and Lactobacillus plantarum during sourdough fermentation: identification of novel compounds and long-term effect during storage of wheat bread. Appl Environ Microbiol. 2011;77(10):3484-92.

26. Sanchez-Machado DI, Lopez-Cervantes J, Martinez-Cruz O. Quantification of organic acids in fermented shrimp waste by HPLC Food Technol. Biotechnol.2008;46(4):456-60.

27. Abdallah OM, Badawey AM. Derivative Ratio Spectrophotometric, Chemometric and HPLC Validated methods for Simultaneous Determination of amlodipine and atorvastatin in combined dosage form. Int J Ind Chem. 2011;2(2):78-85.

28. De Keersmaecker SC, Verhoeven TL, Desair J, Marchal K, Vanderleyden J, Nagy I. Strong antimicrobial activity of Lactobacillus rhamnosus GG against Salmonella typhimurium is due to ac cumulation of lactic acid. FEMS Microbiol Lett. 2006;259(1):89-96.

29. Luzzaro F, Mantengoli E, Perilli M, Lombardi G, Orlandi V, Orsatt A, et al. Dynamics of a nosocomial outbreak of multidrug-resistant Pseudomonas aeruginosa producing the PER-1 extendedspectrum beta-lactamase. J Clin Microbiol. 2001;39(5):1865-70.

30. Magnet S, Blanchard JS. Molecular insights into aminoglycoside action and resistance. Chem Rev. 2005;105(2):477-98.

31. Bryan LE, O'Hara K, Wong S. Lipopolysaccharide changes in impermeability-type aminoglycoside resistance in Pseudomonas aeruginosa. Antimicrob Agents Chemother.1984;26(2):250-5.

32. Galbraith L, Wilkinson SG, Legakis NJ, Genimata V, Katsorchis TA Rietschel ET. Structural alterations in the envelope of a gentamicin-resistant rough mutant of Pseudomonas aeruginosa. Ann Microbiol (Paris). 1984;135B(2):121-36.

33. Flanders SA, Collard HR, Saint S. Nosocomial pneumonia: state of the science. Am J Infect Control. 2006;34(2):84-93.

34. Velraeds MM, van der Mei HC, Reid G, Busscher HJ. Inhibition of initial adhesion of uropathogenic Enterococcus faecalis to solid substrata by an adsorbed biosurfactant layer from Lactobacillus acidophilus. Urology. 1997;49(5):790-4.

35. Vodnar DC, Paucean A, DULF FV, Socaciu C. HPLC characterization of lactic acid formation and FTIR fingerprint of probiotic bacteria during fermentation processes. Notulae Botanicae Horti Agrobotanici Cluj-Napoca. 2010;38(2):109-13.

36. Yang Z. Antimicrobial compounds and extracellular polysaccharides produced by lactic acid bacteria: structures and properties.Finland department of food technology, University of Helsinki; 2000.

37. Smulders FJM, Barendsen P, Van Logtestijn JG, Mossel DAA, Van Der Marel GM. Review: Lactic acid: considerations in favour of its acceptance as a meat decontamininant. Int J Food Sci Technol. 2007;21(4):419-36.

38. Earnshaw RG. The antimicrobial action of lactic acid bacteria: natural food preservation systems. In: Wood BJB editor. The Lactic Acid Bacteria.. UK: Springer; 1992. pp. 211-32.

39. Kong S, Davison AJ. The role of interactions between $\mathrm{O} 2, \mathrm{H} 2 \mathrm{O} 2$, $\mathrm{OH}, \mathrm{e}-$ and $\mathrm{O} 2$ - in free radical damage to biological systems. Arch Biochem Biophys. 1980;204(1):13-29.

40. Alakomi HL, Skytta E, Saarela M, Mattila-Sandholm T, Latva-Kala $\mathrm{K}$, Helander IM. Lactic acid permeabilizes gram-negative bacte- 
ria by disrupting the outer membrane. Appl Environ Microbiol. 2000;66(5):2001-5.

41. Goswami M, Mangoli SH, Jawali N. Involvement of reactive oxygen species in the action of ciprofloxacin against Escherichia coli. Antimicrob Agents Chemother. 2006;50(3):949-54.

42. Sanders ME, Akkermans LM, Haller D, Hammerman C, Heimbach J, Hormannsperger G, et al. Safety assessment of probiotics for human use. Gut Microbes. 2010;1(3):164-85.

43. Snydman DR. The safety of probiotics. Clin Infect Dis. 2008;46 Suppl 2:S104-11.

44. Saarela M, Mogensen G, Fonden R, Matto J, Mattila-Sandholm T. Probiotic bacteria: safety, functional and technological properties. J Biotechnol. 2000;84(3):197-215.

45. Senok AC, Ismaeel AY, Botta GA. Probiotics: facts and myths. Clin Microbiol Infect. 2005;11(12):958-66.

46. Cannon JP, Lee TA, Bolanos JT, Danziger LH. Pathogenic relevance of Lactobacillus: a retrospective review of over 200 cases. Eur J Clin Microbiol Infect Dis. 2005;24(1):31-40.
47. Kunz AN, Noel JM, Fairchok MP. Two cases of Lactobacillus bacteremia during probiotic treatment of short gut syndrome. J Pediatr Gastroenterol Nutr. 2004;38(4):457-8.

48. De Groote MA, Frank DN, Dowell E, Glode MP, Pace NR. Lactobacillus rhamnosus GG bacteremia associated with probiotic use in a child with short gut syndrome. Pediatr Infect Dis J. 2005;24(3):278-80.

49. Ledoux D, Labombardi VJ, Karter D. Lactobacillus acidophilus bacteraemia after use of a probiotic in a patient with AIDS and Hodgkin's disease. Int J STD AIDS. 2006;17(4):280-2.

50. Kalima P, Masterton RG, Roddie PH, Thomas AE. Lactobacillus rhamnosus infection in a child following bone marrow transplant. J Infect. 1996;32(2):165-7.

51. Salyers AA, Gupta A, Wang Y. Human intestinal bacteria as reservoirs for antibiotic resistance genes. Trends Microbiol. 2004;12(9):412-6.

52. Mathur S, Singh R. Antibiotic resistance in food lactic acid bacteria--a review. Int J Food Microbiol. 2005;105(3):281-95. 